\title{
Zusammenarbeit funktioniert
}

AUTORIN: ANITA WUTTKE

Von 2005 bis 2016 galt die Zusammenarbeit der beiden Schwesterkörperschaften KZVB und Bayerische Landeszahnärztekammer (BLZK) als verbesserungswürdig. Insbesondere in der KZVB war in den vergangenen sechs Jahren bis 2016 eine Closed-Shop-Politik betrieben worden, die sich bis in die acht zahnärztlichen Bezirke negativ auswirkte. Die Stagnation und Intransparenz innerhalb der KZVB hatte der FVDZ in Bayern in den Vertreterversammlungen der KZVB thematisiert und auch öffentlich gemacht. 2016 wählten die bayerischen Zahnärzte das alte System ab. Seit 1. Januar 2017 stellt der FVDZ-Landesverband Bayern die Mehrheit der Delegierten in beiden Körperschaften. Und seither setzt das Team des Freien Verbandes in der KZVB kontinuierlich um, was der Verband im Wahlkampf versprochen hatte.

\section{ZAHNÄRZTE SPRECHEN MIT EINER STIMME}

Die Vollversammlung der BLZK und die Vertreterversammlung der KZVB förderten zutage, was in einem Jahr erreicht wurde: Die bayerischen Zahnärzte sprechen nun tatsächlich mit einer Stimme.

- BLZK und KZVB firmieren nach außen unter der gemeinsamen Dachmarke „Die bayerischen Zahnärzte" und treten bei Messen und Kongressen gemeinsam auf.

- Im Bereich der Fortbildung gibt es keine Konkurrenzveranstaltungen mehr, auch hier wird auf Gemeinsamkeit gesetzt. - Die Pressestellen arbeiten zusammen, was sich darin zeigt, dass in den Publikationen die Informationen an die Zahnärzte klar formuliert sind.

- Bei der Unterstützung im berufsbegleitenden/berufspolitischen Bereich ziehen die Referate an einem Strang, ebenso in den Bereichen Praxisführung, Qualitätssicherung und -management sowie Gutachterwesen, um die wichtigsten zu nennen. - Ausschüsse werden paritätisch besetzt und bilden die Verhältnisse in den Delegiertenversammlungen ab.

- Einsame Entscheidungen des KZVB-Vorstands gibt es seit 2017 nicht mehr. Die Fachkompetenz der Geschäftsbereiche fließt mit ein.

\section{|}

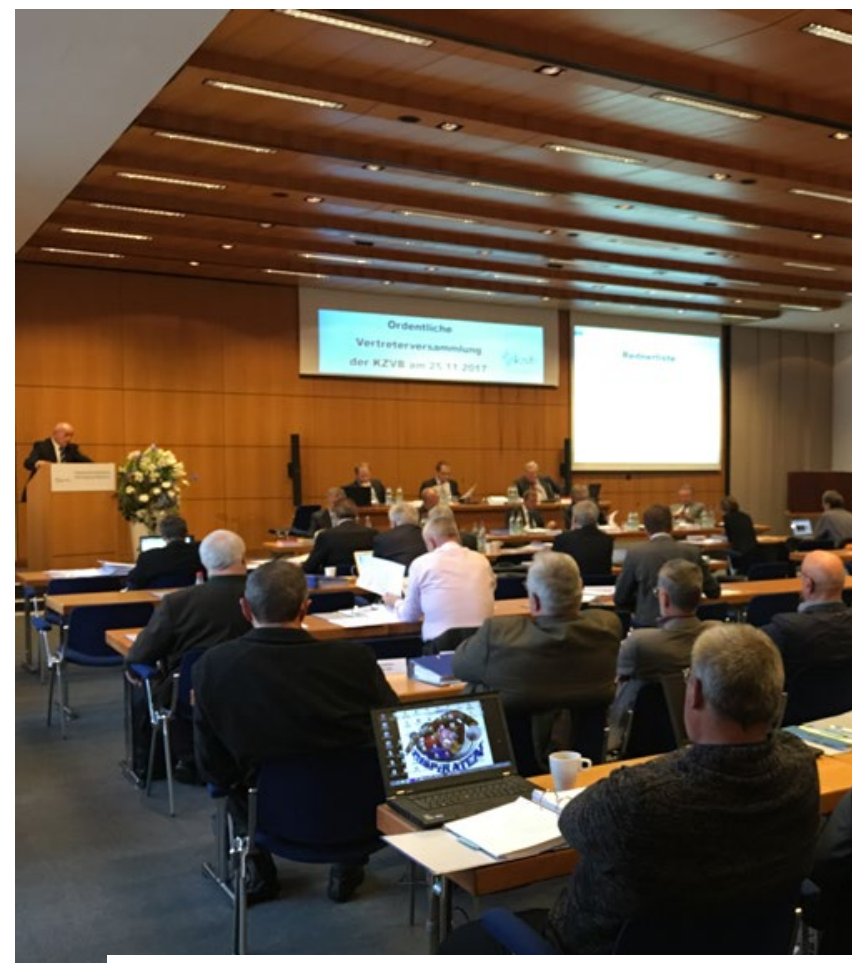

Mehr Mitsprache, mehr Transparenz: In der KZVB ist die Closed-Shop-Politik Vergangenheit.

\section{JEDE MENGE SYNERGIEEFFEKTE AUSGELÖST}

„Längst sind nicht alle Probleme gelöst, die uns die bisherige Vorstandschaft und die sie tragende Fraktion in der Vertreterversammlung der KZVB hinterlassen haben. Aber im Hinblick auf die BLZK lässt sich jetzt bereits feststellen, dass die Zusammenarbeit eine ganze Menge Synergieeffekte ausgelöst hat", sagt Christian Berger, der gemeinsam mit Dr. Rüdiger Schott an der Spitze der beiden Körperschaften steht und gleichzeitig als Landesvorsitzender des FVDZ für die Umsetzung der Ziele des FVDZ in den Körperschaften verantwortlich zeichnet. 